\title{
Preparation and Properties of Composite PAN/PANI Membranes
}

\author{
Beata Fryczkowska, Zofia Piprek, Marta Sieradzka, \\ Ryszard Fryczkowski, and Jarosław Janicki
}

Institute of Textile Engineering and Polymer Materials, University of Bielsko-Biala, Willowa 2, 43-309 Bielsko-Biala, Poland

Correspondence should be addressed to Beata Fryczkowska; bfryczkowska@ath.bielsko.pl

Received 9 October 2016; Revised 27 November 2016; Accepted 14 December 2016; Published 8 February 2017

Academic Editor: Bernabé L. Rivas

Copyright (C) 2017 Beata Fryczkowska et al. This is an open access article distributed under the Creative Commons Attribution License, which permits unrestricted use, distribution, and reproduction in any medium, provided the original work is properly cited.

\begin{abstract}
The methods of modifying PAN membranes have been known and used for many years. An interesting solution seems to be to give the sensory properties to this type of membranes. This paper presents the results of research on the method of obtaining PAN/PANI membranes using phase inversion method from a solution in DMF, following two methods: (1) dissolving both polymers (PAN and PANI) and then coagulating in water or in an aqueous solution of CSA and (2) forming the membranes from polyacrylonitrile solution and coagulation in water, followed by coating of CSA with a solution of TFE. The membranes obtained as a result of the experiment were tested for physical and chemical properties, transport properties, surface morphology, degree of dispersion of composite components, and sensitivity to the presence of dilute acids and bases. FTIR microspectroscopy and scanning electron microscopy were used to study the surface morphology. The sensory properties of membranes that are inherently colored were determined visually and by UV-Vis spectrophotometry. Furthermore, when choosing the method of membrane forming, we can obtain membranes with good physical and chemical and transport properties or ones characterized by high sensitivity to the $\mathrm{pH}$ of the solution.
\end{abstract}

\section{Introduction}

Polyacrylonitrile (PAN) was first synthesized in 1920 by Herbert Reina. In 1942, DuPont obtained the fiber (Orlon) by spinning from a solution of the polymer in $\mathrm{N}, \mathrm{N}$-dimethylacetamide [1]. Polyacrylonitrile fibers rank third in terms of production among all synthetic fibers [2]. High interest in the fibers is due to their performance properties, such as high thermal conductivity, UV resistance, mechanical strength, and high chemical resistance [2].

PAN is an inexpensive and popular engineering polymer, which in addition to the classical textile industry is widely used in special clothing for the army [3], medical and antibacterial clothing [4], superhydrophobic surface finishes [5], as a component of various types of composites [6], and moreover in electrical devices [7], optoelectronic, photonic devices [8], and energy storage systems [9]. Polyacrylonitrile has strong electrostatic properties that facilitate the attraction of microbes and dust particles [10] and therefore it was used in high performance dust removal filters and for disposal of toxic compounds [11]. In addition, the polymer has found wide application in various types of biosensors [12].

PAN is soluble in various solvents and it can be formed from solution. These solvents are DMF, DMSO, DMA, chloroacetonitrile, dioxanone, dimethyl phosphite, dimethyl sulfone, $\gamma$-butyrolactone, ethylene carbonate, nitric acid, and sulfuric acid [1]. Membranes obtained from PAN are characterized by high mechanical strength, and therefore they are used in pressure membrane processes: ultrafiltration (UF), nanofiltration (NF), reverse osmosis (RO), and pervaporation (PV) [13-16]. Among the factors that affect the morphology of the membrane during the phase inversion forming, and thus its properties, among others, polymer concentration, the type of solvent and the coagulant used and the time of solvent evaporation can certainly be distinguished $[15,17,18]$. In addition to these factors, the use of various types of organic or inorganic additives also significantly affects the properties of the obtained membranes [19]. In 


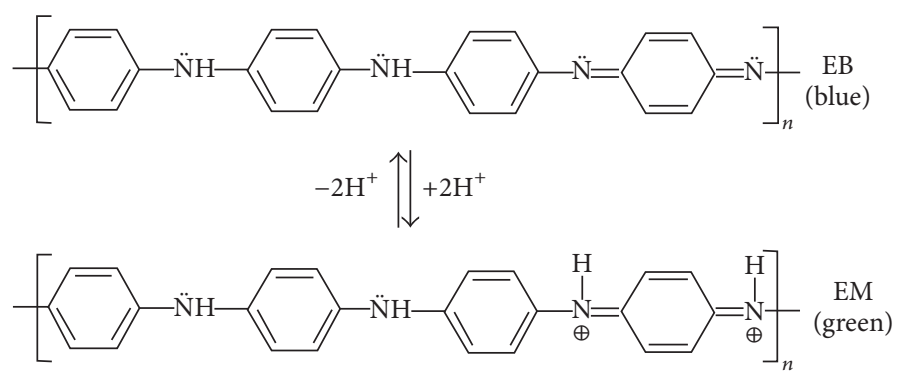

FIGURE 1: Chemical structure of polyaniline.

order to increase the hydrophilic properties and to reduce fouling, polyacrylonitrile can be chemically modified relatively easily, for example, by primary amines, by sodium hydroxide treatment, or by physical surface treatment using plasma $[13,20]$. An interesting solution seems to be to enrich polyacrylonitrile with conductive polymer in order to evacuate charges accumulated on the membrane and reduce fouling.

Conducting polymers, which include polyacetylene, polypyrrole, polyaniline, and polythiophene, are very popular because of the interesting physical properties, which make them suitable for use in light-emitting diodes, field effect transistors, photovoltaic cells [21, 22], sensors [23], wastewater treatment $[24,25]$, separation of ions $[26,27]$, and so forth. The first Polish conducting polymer is polyaniline (PANI) obtained at the turn of 1974-1975 by J. Langer. It is characterized by easy and inexpensive method of preparation [28] and good electrical properties and thermal and chemical stability, so that it is used in batteries, capacitors, and anticorrosion and antistatic coatings [29-31]. Polyaniline has the ability to change the conductivity and color under the influence of various chemical agents. This feature makes it well suited for the production of detectors, sensors, and biosensors which can detect, among others, reducing sugars, urease, ammonia, and many other compounds [31-34]. In the case of optical sensors in which PANI is used, the reversible reaction of protonation/deprotonation of polyaniline, which proceeds according to Figure 1, is of particular importance.

The transition from a conductive form of PANI (EM) to its nonconductive form (EB) is associated with changes in the UV-Vis-NIR spectrum [35]. The green emeraldine salt shows the characteristic absorbance peaks at 800 and $430 \mathrm{~nm}$, while the deprotonated form results in a blue emeraldine base for which the absorbance peak can be seen at 630 and $330 \mathrm{~nm}$ [36].

The literature indicates various techniques for the preparation of polyacrylonitrile membranes with the addition of polyaniline. Miao et al. [37] describe a technique in which PAN nanofibers obtained by electrospinning constitute the membrane carrier on which a solution of aniline is added and then polymerized. Other works describe a technique of obtaining the composite from protonated form of polyaniline dissolved and mixed with PAN solution in dimethyl sulfoxide (DMSO), with a film poured and dried at elevated temperature $\left(60^{\circ} \mathrm{C}\right)[38]$, and other authors used this solution to manufacture membrane by electrospinning [39]. Zhai et al.
[40] used the phase inversion method to obtain the composite membrane by casting PAN+aniline/DMSO polymer film and then by polymerization of PANI and coagulation of the membrane. In other works, homogeneous solution of PAN+aniline was added to the mixture of coagulant containing oxidant in which the polymerization of PANI and coagulation of fibers occurred simultaneously [41]. Still other authors describe a method wherein the phase inversion method is used to precipitate membrane from PAN on a platinum electrode, on which PANI is electrochemically polymerized [42, 43]. Bayramoglu et al. [44], on the other hand, described a technique for preparing the membrane of polyacrylonitrile, which was immersed in PANI polymerization solution.

This paper presents the results of tests of physical and chemical, transport, and sensory properties and the surface morphology of the membranes of polyacrylonitrile enriched with polyaniline. The membranes were obtained by phase inversion in two different ways. The first one consisted in the use of a solvent common for both polymers, N,Ndimethylformamide (DMF), which was used to prepare a solution and then coagulated in water or an aqueous solution of camphorsulfonic acid (CSA). The second one was manufacturing the membrane from PAN solution in DMF, followed by coagulation in distilled water, drying, and coating with a solution of protonated polyaniline in 2,2,2-trifluoroethanol (TFE) [45].

\section{Experimental}

2.1. Materials. PAN-statistical terpolymer (93 94 wt.\% acrylonitrile, 5 6 wt.\% methyl acrylate, and approx. 1 wt.\% sodium allylsulfonate) was produced by Zoltek. PANI ( $\mathrm{Mw}=$ 50,000), camphorsulfonic acid (CSA), and 2,2,2-trichloroethanol (TFE) were purchased from Sigma-Aldrich. N,Ndimethylformamide (DMF) was purchased from Avantor Performance Materials Poland S.A.

\subsection{Membrane Forming}

2.2.1. Forming of PAN Membranes. Polyacrylonitrile membranes were obtained using phase inversion method. Firstly, we prepared $12 \mathrm{wt}$ \% polymer solution in N,N-dimethylformamide (DMF) at a room temperature. The PAN solution was then poured onto a glass plate and spread with an applicator with a gap width of $0.1 \mathrm{~mm}$. Immediately after forming of the film it was coagulated in distilled water at a room temperature until the membrane came away of the glass. The precipitated 
membranes (" 0 " membrane) were dried under a load in air (between two sheets of filter paper loaded with glass plate).

2.2.2. Forming of Composite PAN/PANI Membranes. To prepare the polyacrylonitrile (PAN) membranes containing polyaniline (PANI), two preparation methods were used. The first method consisted in the preparation of a solution containing both polymers (PAN/PANI), and then the membranes were wet-formed by phase inversion. The second method consisted in wet-forming membranes of polyacrylonitrile then coating with a solution of polyaniline in TFE.

Method 1. 1 wt.\% solution of PANI in DMF was prepared. Then polyacrylonitrile was added to it in an amount such that the concentration of the polymer was $12 \mathrm{wt} . \%$. The resulting solution was used to form membranes using phase inversion method. For this purpose, the polymer solution was poured on a glass plate and using an applicator with a slot width of $0.1 \mathrm{~mm}$ polymer film was formed. Then it was immediately coagulated in three different baths at room temperature until the membrane came away of the glass. The coagulation baths were (a) water (A membrane); (b) water, followed by $0.1 \mathrm{M}$ solution of camphorsulfonic acid for $30 \mathrm{~s}$ (B membrane); and (c) $0.1 \mathrm{M}$ solution of camphorsulfonic acid (C membrane). The resulting membranes were dried under a load in air (between two sheets of a filter paper loaded with a glass plate).

Method 2. 12 wt.\% solution of PAN in DMF was poured on a leveled glass plate and using a casting knife with a gap width of $0.1 \mathrm{~mm}$ polymer film was molded. The membranes were then immediately coagulated in water and then dried under a load in air (between two sheets of a filter paper loaded with a glass plate). Then a $0.36 \mathrm{wt}$. $\%$ solution of polyaniline (PANI) in 2,2,2-trichloroethanol (2.2 $\mathrm{g}$ of CSA added for every $2 \mathrm{~g}$ of PANI) was prepared, in which the membranes of pure polyacrylonitrile were immersed and then dried in air (D membrane).

2.3. General Characterization. Thickness $(l)$ of the membranes was measured with ELMETRON MG-1 thickness gauge. Samples with dimensions of $1 \times 1 \mathrm{~cm}$ were weighed using SARTORIUS CP224S-0CE analytical balance with an accuracy of $0.0001 \mathrm{~g}$.

The mass per unit area $\left(W_{s}\right)$ of the membranes $\left(\mathrm{g} / \mathrm{cm}^{2}\right)$ and the density $\left(d_{m}\right)$ of the membranes $\left(\mathrm{g} / \mathrm{cm}^{3}\right)$ were calculated using the following formulas:

$$
\begin{aligned}
& W_{s}=\frac{w}{s}, \\
& d_{m}=\frac{w}{s \times l},
\end{aligned}
$$

where $w$ is the weight of a membrane with an area of $1 \mathrm{~cm}^{2}, s$ is membrane surface area $\left[\mathrm{cm}^{2}\right]$, and $l$ is membrane thickness $[\mathrm{cm}]$.

The static contact angle was measured using a goniometer (FIBRO System AB PG-1); thus the tests were made in the skin (top) layer of the membranes.
The porosity of the membranes $(\varepsilon)$, which is defined as the ratio of pore volume to the volume of the membrane, was calculated using the following formula [46]:

$$
\varepsilon=\frac{\left(w_{1}-w_{2}\right) / d_{w}}{\left(w_{1}-w_{2}\right) / d_{w}+w_{2} / d_{p}} \times 100 \%,
$$

where $w_{1}$ is wet sample weight $(\mathrm{g}) ; w_{2}$ is dry sample weight $(\mathrm{g}) ; d_{w}$ is density of distilled water $\left(0.998 \mathrm{~g} / \mathrm{cm}^{3}\right) ; d_{p}$ is polymer density $\left(1.17 \mathrm{~g} / \mathrm{cm}^{3}\right.$; properties obtained from Zoltek company).

2.4. Transport Properties. Transport properties of the obtained membranes were tested using a Millipore's Amicon 8400 ultrafiltration cell with a capacity of $350 \mathrm{~cm}^{3}$ and a membrane diameter of $7.6 \mathrm{~cm}$. The membranes were used for 2 hours under a pressure of 0.2 MPa. From our experience, it has positive effect on the stability of a membrane. Then they were tested at an operating pressure of $0.05,0.1,0.15$, and $0.2 \mathrm{MPa}$. Permeate flux $\left(J_{v}\right)$ was calculated using the following formula:

$$
J_{v}=\frac{Q}{A \times t},
$$

where $J_{v}$ is water flux $\left(\mathrm{L} / \mathrm{m}^{2} \times \mathrm{h}\right), Q$ is the volume of water permeate $(\mathrm{L}), A$ is the effective membrane area $\left(\mathrm{m}^{2}\right)$, and $t$ is the permeation time $(h)$.

The pore size $\left(r_{m}\right)$ was determined using Guerout-ElfordFerry equation [see (4)] on the basis of the pure water flux and porosity data was used [47]:

$$
r_{m}=\sqrt{\frac{(2.9-1.75 \varepsilon) 8 \eta l Q}{\varepsilon \times A \times \Delta P}},
$$

where $\eta$ is the water viscosity $\left(8.9 \times 10^{-4} \mathrm{~Pa} \cdot \mathrm{s}\right), l$ is the membrane thickness ( $\mathrm{m}), Q$ is the volume of permeated pure water per unit of time $\left(\mathrm{m}^{3} / \mathrm{s}\right), A$ is the effective membrane area $\left(\mathrm{m}^{2}\right)$, and $\Delta P$ is the operational pressure.

Mapping the surface of the membranes was made using "Continuum" microscope coupled with Nicolet 6700 FTIR spectrophotometer with a field-emission resolution of $50 \times$ $50 \mu \mathrm{m}$ and linear step-scan of $50 \mu \mathrm{m}$.

The surface morphologies of the skin layer and the support layer as well as membrane sections were examined using a scanning electron microscope (JEOL JSM 5500LV).

2.5. Testing of PAN/PANI Membranes Sensitivity to the Solution $\mathrm{pH}$. The use of polyaniline as a conductive polymer was motivated by the possibility of easy visual observation of changes in the color of the polymer in the protonated, conductive form (green) and nonprotonated, nonconductive form (blue).

In order to verify the sensitivity of obtained membranes to the external environment, 10 dilutions were prepared of $\mathrm{HCl}$ and $\mathrm{NH}_{4} \mathrm{OH}$ solutions at concentrations ranging from $0.1 \mathrm{M}$ to $0.00001 \mathrm{M}$. Then, for each type of membrane, samples with dimensions of $2 \times 2 \mathrm{~cm}$ were cut off. Each sample was immersed for $10 \mathrm{~s}$ in the solutions for each $\mathrm{HCl}$ 
and $\mathrm{NH}_{4} \mathrm{OH}$ concentration and then air-dried. Absorption spectra were measured using UV-Vis Perkin-Elmer Lambda 35 spectrophotometer in the range of $190 \sim 1100 \mathrm{~nm}$ and a scanning speed of $240 \mathrm{~nm} / \mathrm{min}$.

\section{Research Results and Their Analysis}

3.1. Characteristics of Membranes. Polyacrylonitrile is a polymer that is well known and well described in the literature and is widely used both in pure form and with additives. Particularly interesting properties of the polymer are obtained by the introduction of polyaniline as the composite component. Among the enormous number of methods for mixing these two polymers, the most interesting appears to be the use of a solvent common to polyacrylonitrile and polyaniline. Such a solvent is obviously N,N-dimethylformamide, which forms homogeneous solutions both with PAN and with PANI. The scope of research in the described paper is PAN/PANI membranes produced by phase inversion through the polymer coagulation in a nonsolvent (wet method). The article shows how the methods of introducing polyaniline to the membrane and the type of the coagulating bath affect the structure and physicochemical properties of the resulting membranes. The following measurements and calculations were carried out: thickness, mass per unit area, density, contact angle, sorption, porosity, pore size, permeate flux, dispersing of the components on the membrane surface, and sensitivity to changes in acidity $(\mathrm{pH})$ of the aqueous solutions as well as the surface and cross sections morphology. The resulting membranes were flexible, just as in Zhai et al. [40], making it easy to work with them.

The study of mass per unit area (Figure 3(a)) shows that the mass of D membrane is comparable to the mass of pure PAN membrane or even slightly higher. The increase in mass of $\mathrm{D}$ membrane is caused by a thin polyaniline film formed on the surface of the membrane. On the other hand, the membranes prepared from a homogeneous solution of PAN/PANI polymers are slightly lower in mass, which may be due to the additive of polyaniline, which has an impact on the processes occurring during coagulation. Also, a slight decrease in the mass per unit area of the membranes coagulated in a solution containing camphorsulfonic acid is observed. CSA, which is added to protonate the polyaniline, forms a water soluble amine salt which could reduce the mass of the membranes. During the coagulation process (of membranes A, B, and C), we observed coloration of distilled water coming from polyaniline.

Analyzing the results of thickness measurements of the resulting membranes (Figure $3(\mathrm{~b})$ ), it is observed that D membrane is approximately $13 \%$ thicker than " 0 " membrane which is the result of applying a thin layer of PANI. For membranes formed from a homogeneous PAN/PANI solution and coagulated in water (A membrane), the increase in the thickness in comparison with the pure polyacrylonitrile membranes is nearly double. Such a large increase in the thickness of the membrane may indicate that the hydrophobic polyaniline definitely affects the processes occurring during the coagulation of the membrane, resulting in the formation of highly porous structures. Application of the
CSA solution in coagulation of $\mathrm{C}$ membrane resulted in a decrease in the thickness of the membrane obtained by about $35 \%$ compared to pure PAN membranes. Based on the observed changes, it may be concluded that the coagulation of PAN/PANI membranes in an acid solution leads to the formation of water-soluble polyaniline salt. C membrane's color in the images (Figure 2), after operating in the aqueous environment, has not changed and is still green, which confirms the assumption that the protonated form of polyaniline is not present in the pores of the membrane; that is, it was probably removed in the coagulation process. Feng et al. [48] explain the influence of polymer hydrophobicity or hydrophilicity on membrane coagulation using phase inversion. Their research shows that hydrophobic (PPSU, polyphenylsulfone) polymer coagulates faster.

Method of preparation of $\mathrm{B}$ membrane, consisting in coagulation in water and then a bath containing CSA, results in a decrease in $\mathrm{B}$ membrane thickness as compared to $\mathrm{A}$ membrane. It is believed that during the coagulation in CSA solution polyaniline on the membrane surface and in its pores is protonated. Then, the polyaniline, weakly bound to the polymer matrix, in the soluble form is transferred to water and the thickness of the membrane is reduced. The presence of protonated polyaniline is confirmed by the images (Figure 1) on which the membranes, tested for transport properties, under the impact of distilled water changed color from green to blue.

Calculations of the density of obtained membranes (Figure 3(c)) show that $\mathrm{C}$ membrane is characterized by the greatest density, which indicates its high compactness and low porosity. The densities of " 0 " and D membranes are similar and aligned with their mass per unit area and thickness. The lowest density and, consequently, the highest porosity are found in A membrane. In the case of B membrane, a slightly higher density is observed as compared to A membrane, which, however, does not alter the fact that it is also highly porous.

By studying sorption properties of all obtained membranes (Figure $3(\mathrm{~d})$ ), it must be pointed out that these are very high values in the range of $200 \sim 500 \%$. The lowest water sorption $(191.83 \pm 2.22 \%)$ characteristic is the one for $\mathrm{C}$ membrane, which according to previous studies is the thinnest and has the most compact structure. Similarly, D membrane is very similar with lower water sorption values $(221.29 \pm 2.00 \%)$ than the pure PAN membrane (352.69 \pm 25.16\%). D membrane, which has a thickness and density characteristics similar to A membrane, absorbs much less water than " 0 " membrane. This result could be due to the polyaniline coating of the membrane which in contact with water forms a hydrophilic film which protects the membrane against water. However, sorption of more than $220 \%$ is a high value, which may be due to the lack of continuity of the outer layer of the membrane. A membrane shows the best water sorption of $492.42 \pm 4.22 \%$, which is the result of a large thickness and low density of the membrane. Slightly lower sorption values are shown for B membrane. Analyzing the results, it should be noted that the addition of CSA to the coagulating bath (B and $\mathrm{C}$ membranes) which was aimed at protonating polyaniline in the membrane does not improve 


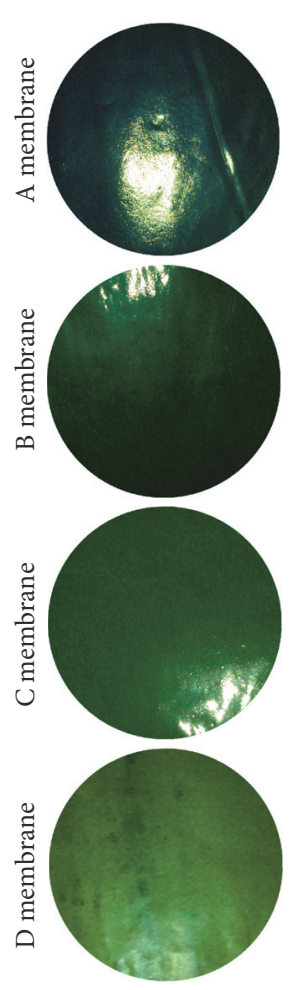

(a)

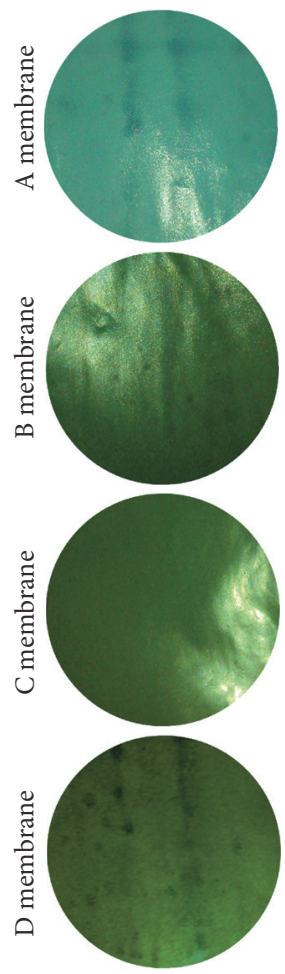

(b)

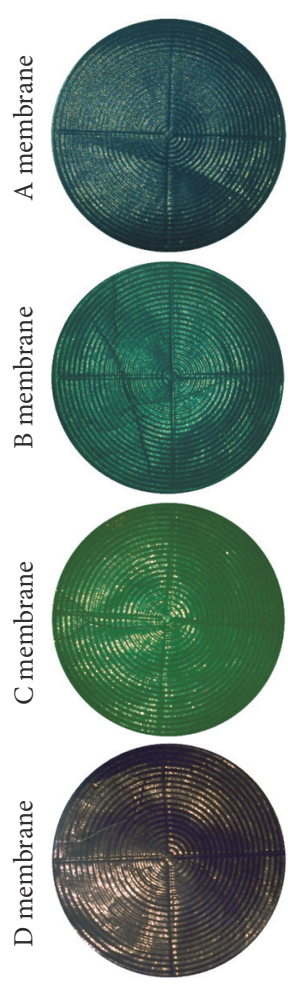

(c)

FIGURE 2: Images of PAN/PANI membrane surfaces: (a) skin layer, (b) carrier layer, and (c) skin layer after transport properties testing.

but deteriorates the sorption properties, which may be related to the chemical structure of the acid used and its arrangement on the surface of the membrane. It is also very likely that a membrane obtained with a coating method (D membrane) behaves the same.

Sorption properties are closely related to the hydrophilic properties which can be tested by contact angle. Pal et al. [49] report that the static contact angle of unmodified polyacrylonitrile membrane was $82.6^{\circ}$. On the other hand, the research team of Tran et al. [13] reports that the contact angle of PAN decreases during plasma treatment from approx. $60^{\circ}$ to approx. $20^{\circ}$. Examining the skin layer of the obtained membranes, it was observed that all of them show strongly hydrophilic properties as their contact angle is in the range of $11 \sim 19^{\circ}$ (Figure 4). Only subtle differences in the contact angle values were observed. " 0 " membrane for which the contact angle was $13.33^{\circ}$ was the reference for the others. The values of the contact angle for A and B membranes are similar but slightly lower than the reference membrane. The observed phenomenon may be due to the presence of nonprotonated PANI (A membrane) and in the case of B membrane the presence of CSA particles, which slightly hydrophobized the membrane surface.

For $\mathrm{C}$ and $\mathrm{D}$ membranes, the highest contact angle values were noted, which may be related to the protonated form if polyaniline was present at the membrane surface. The results obtained indicate that all of the obtained membranes are hydrophilic, so they will not be affected by fouling, and the preparation technique proposed in this paper greatly simplifies and shortens the process for their production.

Porosity calculation for the resulting membranes showed (Table 1 and Figure 3(e)) that A membrane is characterized by the highest porosity, which is confirmed by the results of sorption and contact angle tests. B membrane adopts values similar to A membrane. The membrane made of pure polyacrylonitrile is characterized by a porosity of $80.44 \sim 1.16 \%$. However, according to previous studies and the resulting consequences, the lowest porosity values $(69.22 \pm 0.25 \%)$ are characteristic for $\mathrm{C}$ membrane which has the lowest density and sorption properties. The membrane obtained by coating shows porosity values of approx. $72 \%$, which is consistent with the sorption properties.

3.2. Transport Properties and Pore Sizes. An important parameter determining the transport properties of membranes is the specific permeate flux. The studies (Figure 5) show that $\mathrm{C}$ membrane has the best transport properties in the pressure range of $0.05 \sim 0.2 \mathrm{MPa}$, which may result from its low thickness in comparison to other membranes. SEM images of cross sections (Figure 6) confirm the assumptions, and $\mathrm{C}$ membrane shown on them is different from the others and is characterized by pores perpendicular to its surface. In the case of $\mathrm{B}$ membrane, a decrease in transport characteristics compared to $\mathrm{C}$ membrane is observed. Reports from the literature show that good transport properties are closely related to the high hydrophilicity of membranes [50], which was also achieved in our case. 
TABle 1: Properties of the obtained membranes.

\begin{tabular}{lcccccc}
\hline Membrane & Thickness $[\mu \mathrm{m}]$ & Mass per unit area $\left[\mathrm{g} / \mathrm{cm}^{2}\right]$ & Density $\left[\mathrm{g} / \mathrm{cm}^{3}\right]$ & Contact angle $\left[{ }^{\circ}\right]$ & Water sorption $[\%]$ & Porosity $[\%]$ \\
\hline "0" & $53.5 \pm 4.38$ & $0.00135 \pm 0.00014$ & $0.02515 \pm 0.00263$ & $13.33 \pm 2.50$ & $352.69 \pm 5.16$ & $80.44 \pm 1.16$ \\
A & $103.7 \pm 5.62$ & $0.00110 \pm 0.00010$ & $0.01061 \pm 0.00096$ & $11.25 \pm 1.88$ & $492.54 \pm 4.22$ & $85.24 \pm 0.11$ \\
B & $69.5 \pm 2.69$ & $0.00096 \pm 0.00001$ & $0.01380 \pm 0.00141$ & $11.40 \pm 0.75$ & $412.33 \pm 0.48$ & $82.47 \pm 2.50$ \\
C & $34.8 \pm 2.71$ & $0.00095 \pm 0.00012$ & $0.02728 \pm 0.00335$ & $18.00 \pm 2.50$ & $191.83 \pm 2.22$ & $69.22 \pm 0.25$ \\
D & $60.6 \pm 6.13$ & $0.00137 \pm 0.00009$ & $0.02259 \pm 0.00139$ & $18.57 \pm 1.88$ & $221.29 \pm 2.00$ & $72.17 \pm 0.10$ \\
\hline
\end{tabular}

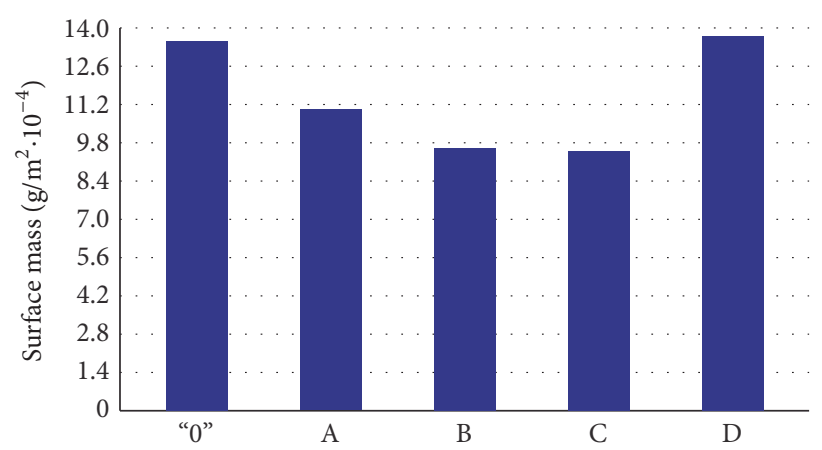

(a)

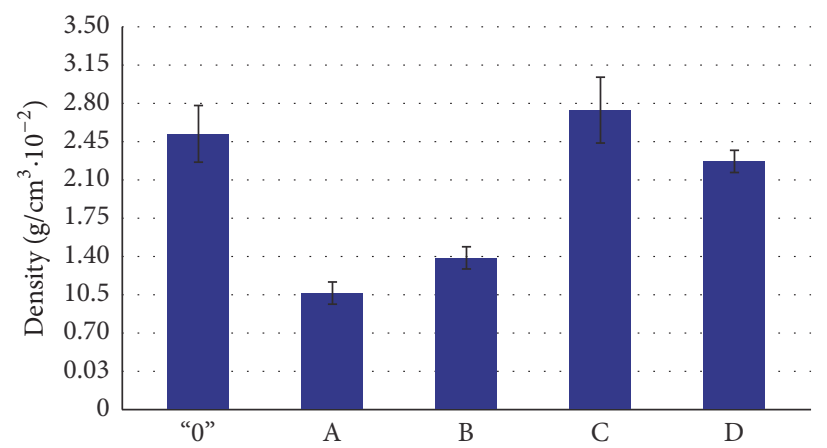

(c)

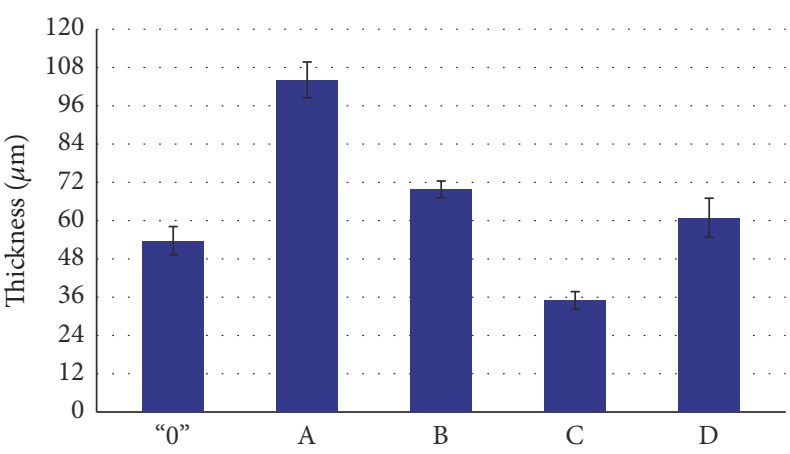

(b)

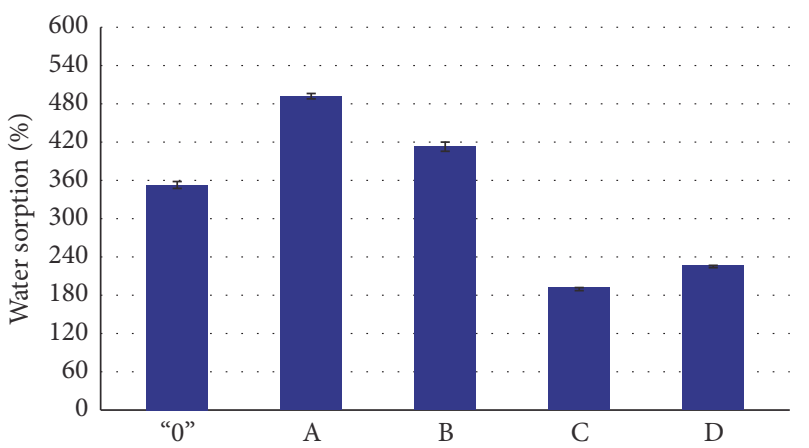

(d)

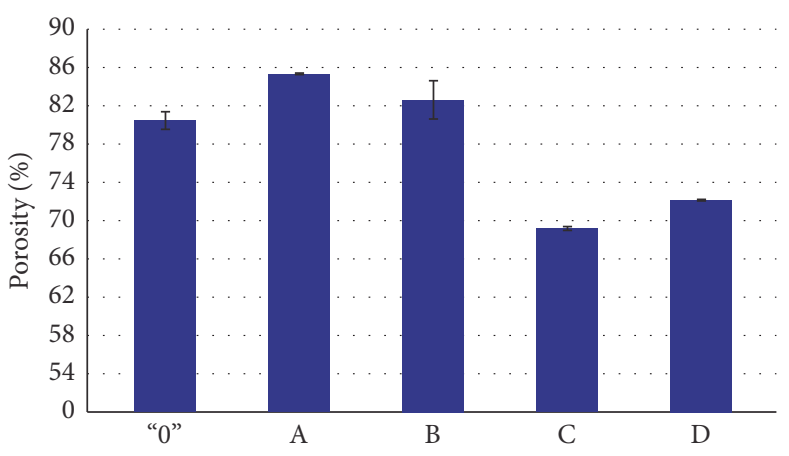

(e)

FIGURE 3: The effect of membrane forming on the thickness, mass per unit area, density, water sorption, and porosity.

"0" and A membranes are characterized by similar specific permeate flux values for all tested operating pressures; however, they are not correlated to the thickness and density. The confirmation of the results of transport properties studies is scanning electron microscope images in which the similarity in the structure of the support can be seen. From our own experience, we know that the arrangement of large chambers in the support observed in cross sections deteriorates transport properties of the obtained membranes.

The lowest specific permeate flux values and thus the worst transport properties are observed in D membrane, which may be due to the compact membrane structure and high density, low water sorption, and cross section morphology the same as in the case of " 0 " and A membranes 
TABLE 2: Permeate flux and pore sizes of membranes.

\begin{tabular}{lccccc}
\hline \multirow{2}{*}{ Membrane } & & Permeate flux $\left[\mathrm{L} / \mathrm{m}^{2} \times \mathrm{h}\right]$ for the transmembrane pressure & $0.2[\mathrm{MPa}]$ & Pore size $[\mathrm{nm}]$ \\
& $0.05[\mathrm{MPa}]$ & $0.1[\mathrm{MPa}]$ & $0.15[\mathrm{MPa}]$ & $48.48 \pm 0.78$ & 7.57 \\
“0” & $14.34 \pm 0.57$ & $29.22 \pm 0.62$ & $40.09 \pm 0.68$ & $53.93 \pm 0.69$ & 33.06 \\
A & $15.73 \pm 0.63$ & $32.38 \pm 0.32$ & $44.56 \pm 0.79$ & $99.13 \pm 1.56$ & 39.11 \\
B & $23.87 \pm 1.11$ & $63.21 \pm 0.79$ & $83.21 \pm 2.36$ & $164.61 \pm 1.58$ & 39.78 \\
C & $49.11 \pm 1.93$ & $94.58 \pm 1.56$ & $139.14 \pm 2.73$ & $16.15 \pm 0.26$ & 28.19 \\
D & $5.22 \pm 0.21$ & $9.74 \pm 0.23$ & $13.36 \pm 0.23$ &
\end{tabular}

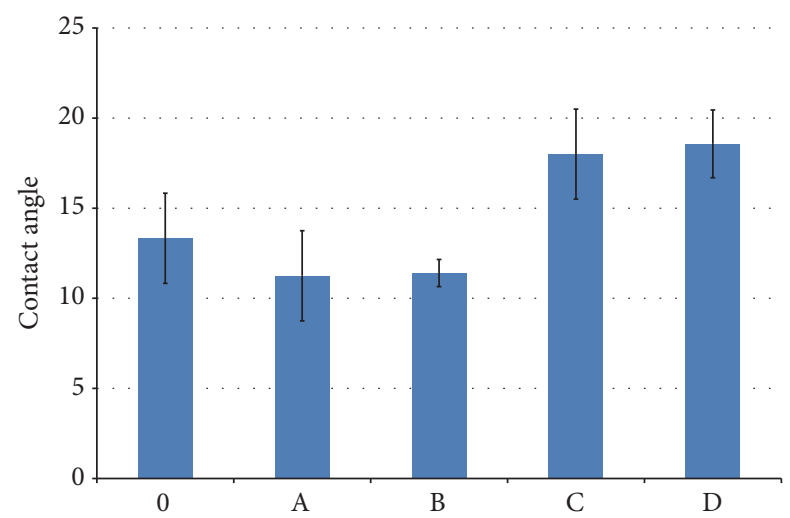

FIGURE 4: The impact of membrane formation on the contact angle values.

(Figure 6). It is also supposed that the low specific permeate flux value is the result of hydrophobization on the surfaces of $\mathrm{D}$ membrane, which is observed in Figure 2 as a change in the membrane color into dark blue with a metallic sheen.

For studied membranes and working pressure of $0.1 \mathrm{MPa}$, the pore size was estimated (formula (3), Table 2) which impacts such variables as porosity, thickness, or specific permeate flux. Calculations show that the pure PAN membrane is composed of the smallest pores, namely, sized $7.57 \mathrm{~nm}$. The pore size of the remaining membranes was estimated at $28 \sim 40 \mathrm{~nm}$. The calculations allowed concluding that the addition of PANI introduced into the membrane itself as well as on its surface significantly affects the morphology of the membrane structure. PAN/PANI membranes obtained from a uniform solution of both polymers have a similar pore size (approximately $39 \mathrm{~nm}$ ) if they are coagulated in CSA solution ( $\mathrm{B}$ and $\mathrm{C}$ membranes), and when coagulated in water ( $\mathrm{A}$ membrane) the pore size is approx. $33 \mathrm{~nm}$. The result obtained for D membrane $(\sim 28 \mathrm{~nm})$, on the other hand, indicates that the process of coating the polyacrylonitrile membranes with protonated polyaniline solution has a significant impact on the estimated pore size.

Surface of cross sections examination of the membranes using scanning electron microscopy (Figure 6) allowed us to observe the impact of forming conditions on the external and internal structure, thickness, and porosity of the membranes. The SEM images show that asymmetric membranes are produced in the forming process. The skin layer of all studied membranes is compact with no visible pores and has a thickness of about $1 \mu \mathrm{m}$.

The surface of the support of pure PAN membrane (" 0 " membrane) has large and numerous porous openings, which

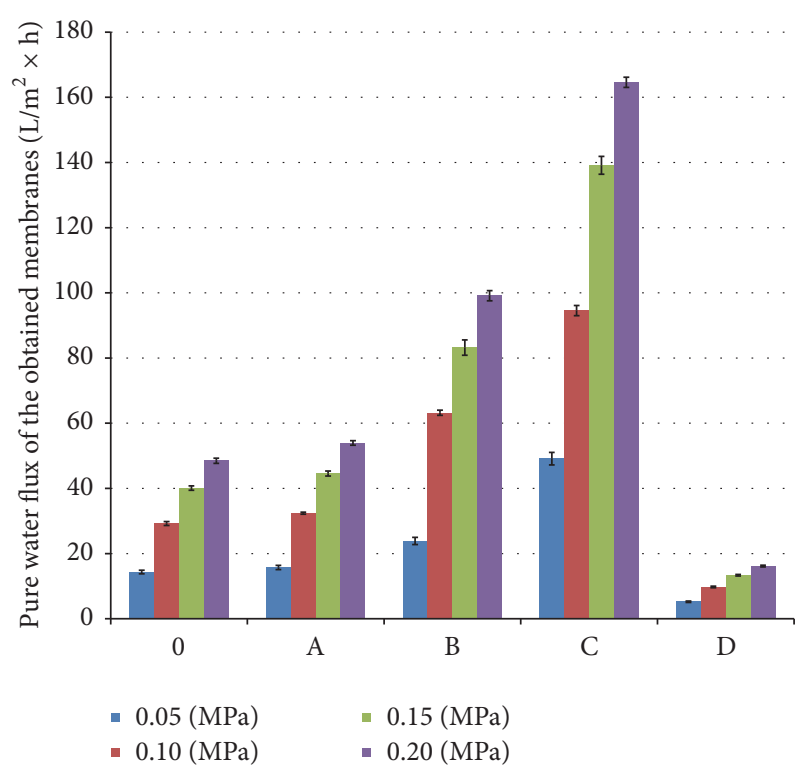

FIGURE 5: Transport properties of membranes.

in the case of D membrane are clearly "sealed" with a polyaniline film. For A membrane, wavy support surface is visible even at low magnification.

On the other hand, the cross sections of " 0 ", $A$, and D membranes show the similarity in thickness of the skin layer $(\sim 1 \mu \mathrm{m})$ and in the structure of the support consisting, in both cases, of large, porous obliquely inclined chambers. " 0 " and $\mathrm{D}$ membranes are similar in thickness, and A membrane is much thicker, which is consistent with the thickness measurement (Table 1). B membrane has a thickness similar to the pure polyacrylonitrile membrane. The cross section SEM images of B membrane show oval chambers in the area of the support, which distinguishes this membrane from the others.

A completely different picture is observed in the cross section of $\mathrm{C}$ membrane, which has a thicker carrier layer $(\sim 1.5 \mu \mathrm{m})$ with asymmetric pores, perpendicular to the surface, which are often reported in the literature $[13,51]$.

3.3. The Degree of Dispersion of Polyaniline in Polyacrylonitrile Matrix. The membranes were tested to determine the degree of dispersion of polyaniline and polyacrylonitrile in the resulting composite. To do this, infrared spectroscopy with surface mapping was used. Based on a distribution of characteristic bands of the individual components of the mixture on the membrane surface, we can specify their share in the total volume (Figure 7). 

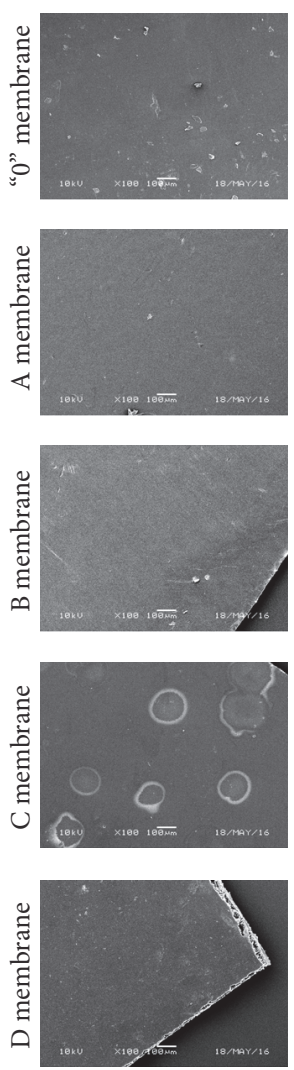

(a)
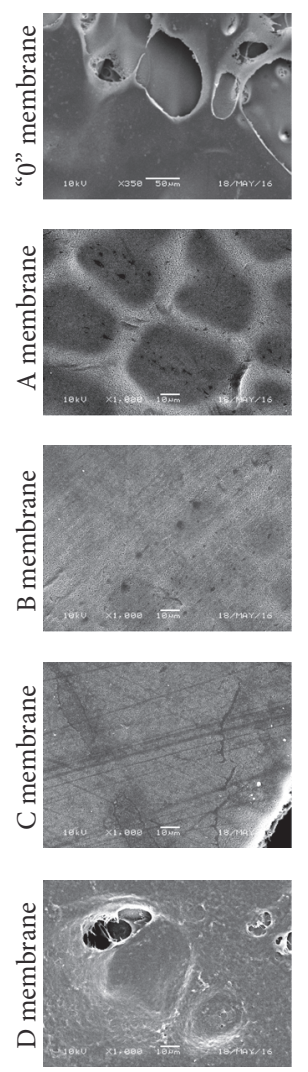

(b)
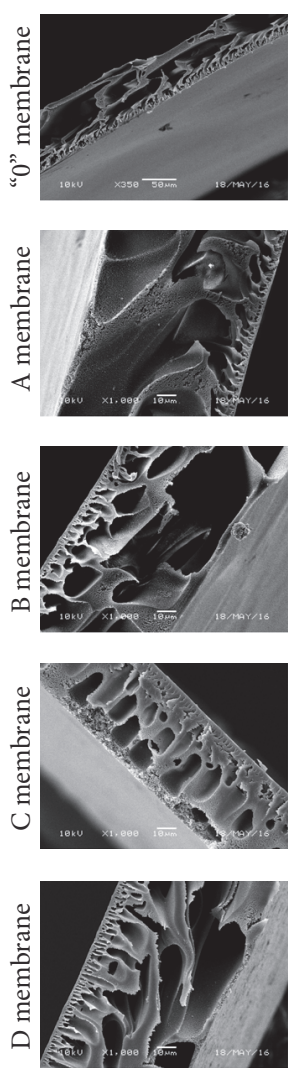

(c)

FIGURE 6: Microphotographs (SEM) of pure PAN and polyaniline-modified membrane cross sections: (a) skin layer; (b) bottom layer; and (c) cross section.

Since each of the membranes was produced using another method, the comparison of the degree of PANI dispersion (which occurs sometimes in a protonated and at other times in nonprotonated form) in the PAN matrix is difficult. In Figure 7, the intensity of $2240 \mathrm{~cm}^{-1}$ band, characteristic of the -CN groups present in the polyacrylonitrile, was analyzed. The highest absorption for the studied wavelength was observed for A membrane, which indicates the PAN presence in both the skin layer (A-1) and the carrier layer (A-2) of the membrane obtained by coagulation in water. The lowest absorption, on the other hand, as supposed, was observed for the surface of PANI coated membrane (D membrane). The absorption spectra of $\mathrm{B}$ and $\mathrm{C}$ membranes are radically different from each other, although they should show many similarities, as a last step of forming for both of them was contact with an aqueous solution of camphorsulfonic acid. In the case of $\mathrm{C}$ membrane, the PAN-derived absorption band disappears, which may indicate the arrangement of protonated polyaniline on the surface of the membrane. However, in the case of B membrane, high intensity in $2240 \mathrm{~cm}^{-1}$ band is observed, which may indicate that the CSA used to protonate PANI penetrates into the membrane pores and that PAN is present on its surface.

In the case of A membrane (Figure 7, A-11 and A-22) and B membrane (Figure 7, B-11 and B-22) intense $803 \mathrm{~cm}^{-1}$ band of polyaniline is observed in the skin layer, and in the carrier layer PANI bands are less intense, though still present. Thus, mixing of the two polymers in a solution and their subsequent coagulation in water leads to formation of membranes in which nonprotonated polyaniline is present in the skin layer. The use of CSA for an additional rinse of already produced membranes, on the other hand, causes PANI protonation and the disappearance of $803 \mathrm{~cm}^{-1}$ band on the membrane surface.

Obtaining PAN/PANI membranes with the use of CSA solution as a coagulant (C-11 and C-22 membranes) leads to the formation of the surface on which a disappearance of characteristic nonprotonated polyaniline band with a wavelength of $803 \mathrm{~cm}^{-1}$ is observed. This effect is the result of washing out of polyaniline, which in the presence of camphorsulfonic acid transforms into a water-soluble salt. Another explanation of the observed phenomena can be "covering" of the membrane surface by CSA. D membranes though, which were coated with a PANI+CSA solution, do not show the presence of nonprotonated polyaniline, as assumed.

The surface mapping method (FTIR) showed that during the formation of membranes of a homogeneous PAN/PANI solution using the wet phase inversion method resulted in membrane components dispersion characteristic of the composite. 

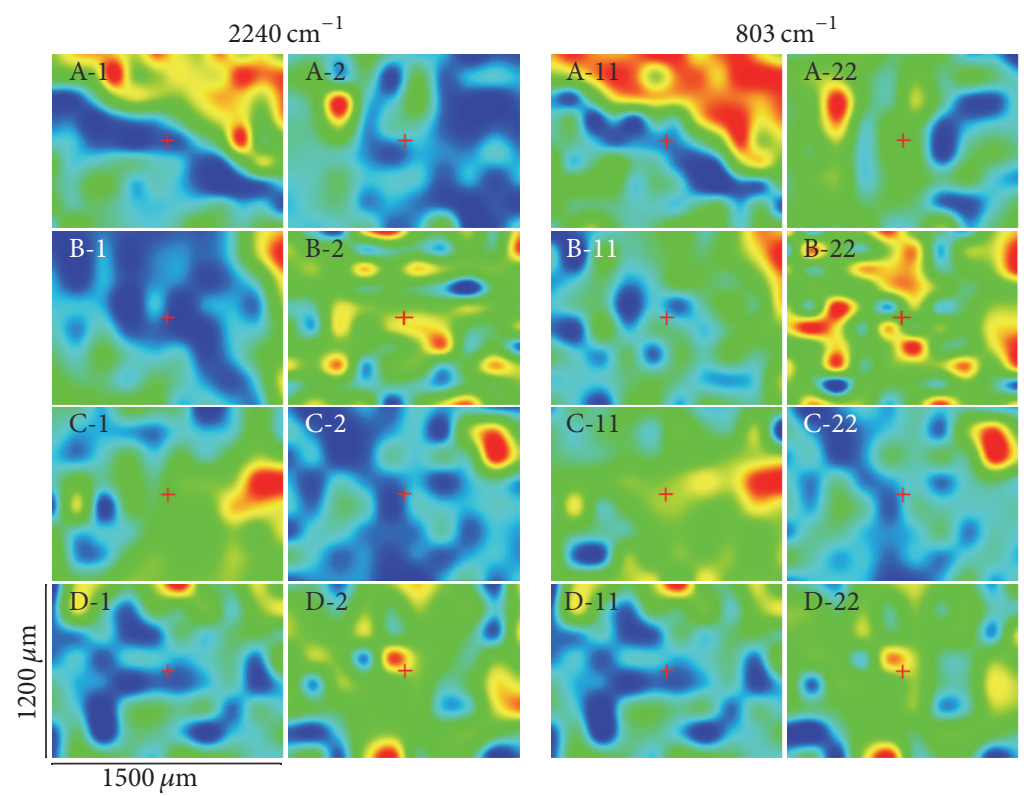

FIGURE 7: Distribution of FTIR absorption bands characteristic for PAN at $2240 \mathrm{~cm}^{-1}$ (1: skin layer, 2: carrier layer) and for PANI at $803 \mathrm{~cm}^{-1}$ (11: skin layer, 22: carrier layer). Red indicates very high absorption in the studied range; blue means no absorption.

3.4. Sensitivity of PAN/PANI Membranes to $p H$ Changes. Polyaniline, due to its electronic structure, has interesting optical properties. As a result of a change in the electronic structure, the compound changes its optical properties in the visible light range. This is mainly manifested by a change in the color of polyaniline solution or film from dark blue to green. This change is caused by changes in the degree of oxidation of the polymer chain under the influence of acidic or alkaline compounds. Changing the degree of oxidation of the polymer chain causes not only a change in color but as proven by MacDiarmid and Epstein [52] it also changes the conformation of the polyaniline polymer chain. The phenomena of changing the chain conformation into a more straight (linear) one is caused by the oxidizing agent, an additive which is usually an acid providing protons (protonation phenomenon). This arrangement of the polymer in space facilitates the excitation of electrons and their movement along the polymer chain. Such an effect results in a rapid increase in the conductivity of polyaniline. This phenomenon can be observed in many ways. One of them is the measurement of conductivity of either solutions or films containing polyaniline. However, in composites or polymer blends, the measurement is hampered by a low polyaniline content, resulting in not exceeding the so-called percolation threshold. Then, continuous conductive phase paths are not formed in the composite structure. This effect is likely to be observed in the studied composite membranes.

In the case of investigated PAN/PANI membranes, it is possible to observe the change in their color with the naked eye. Figure 8 presents the membranes which were treated with dilute solutions of $\mathrm{HCl}$ and $\mathrm{NH}_{4} \mathrm{OH}$ at concentrations of $0.001,0.005,0.0001,0.0005$, and $0.00001 \mathrm{M}$, respectively. These studies were also made for higher concentrations. A membrane, which comprises nonprotonated polyaniline,

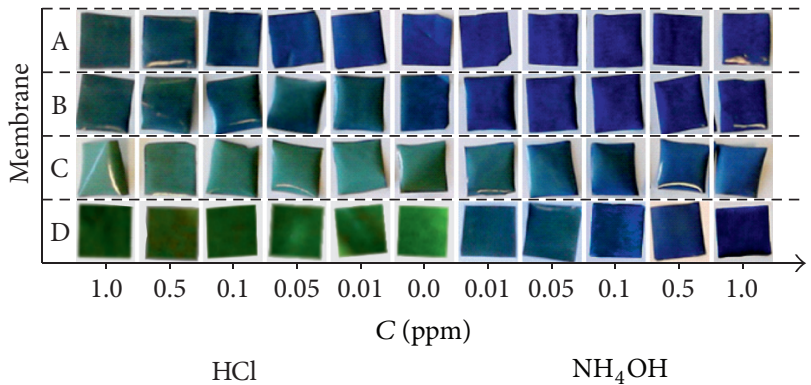

FIGURE 8: Effect of $\mathrm{pH}$ of the solution on the coloration of the PAN/PANI membranes.

changes its coloration at $\mathrm{HCl}$ concentration ratio of $0.1 \mathrm{ppm}$ $(0.0001 \mathrm{M})$, but no coloration change is observed in an alkaline environment. Green-blue color of $\mathrm{B}$ membrane varies under the influence of both $\mathrm{HCl}$ and $\mathrm{NH}_{4} \mathrm{OH}$ with a concentration of $0.01 \mathrm{ppm}(0.00001 \mathrm{M})$. And the PAN/PANI membrane coagulated in CSA solution (C membrane) and PAN membrane coated with protonated PANI (D membrane) change their coloration into blue at $0.01 \mathrm{ppm}(0.00001 \mathrm{M})$ of $\mathrm{NH}_{4} \mathrm{OH}$ solution. The studies show that the membranes of polyacrylonitrile containing protonated form of polyaniline are very sensitive to aqueous ammonia solutions and at a concentration of $0.01 \mathrm{ppm}$ of $\mathrm{NH}_{4} \mathrm{OH}$ a change in their coloration is observed. B membrane was found to be highly sensitive and universal, suitable for use in both acidic and alkaline environments. In contrast, A membrane can be used to detect acid solutions with a concentration greater than $0.1 \mathrm{ppm}$. All the tested membranes change their coloration within 10 seconds. However, in the work by Hoang et al. [53], the investigated sensitivity of the membranes was less than 

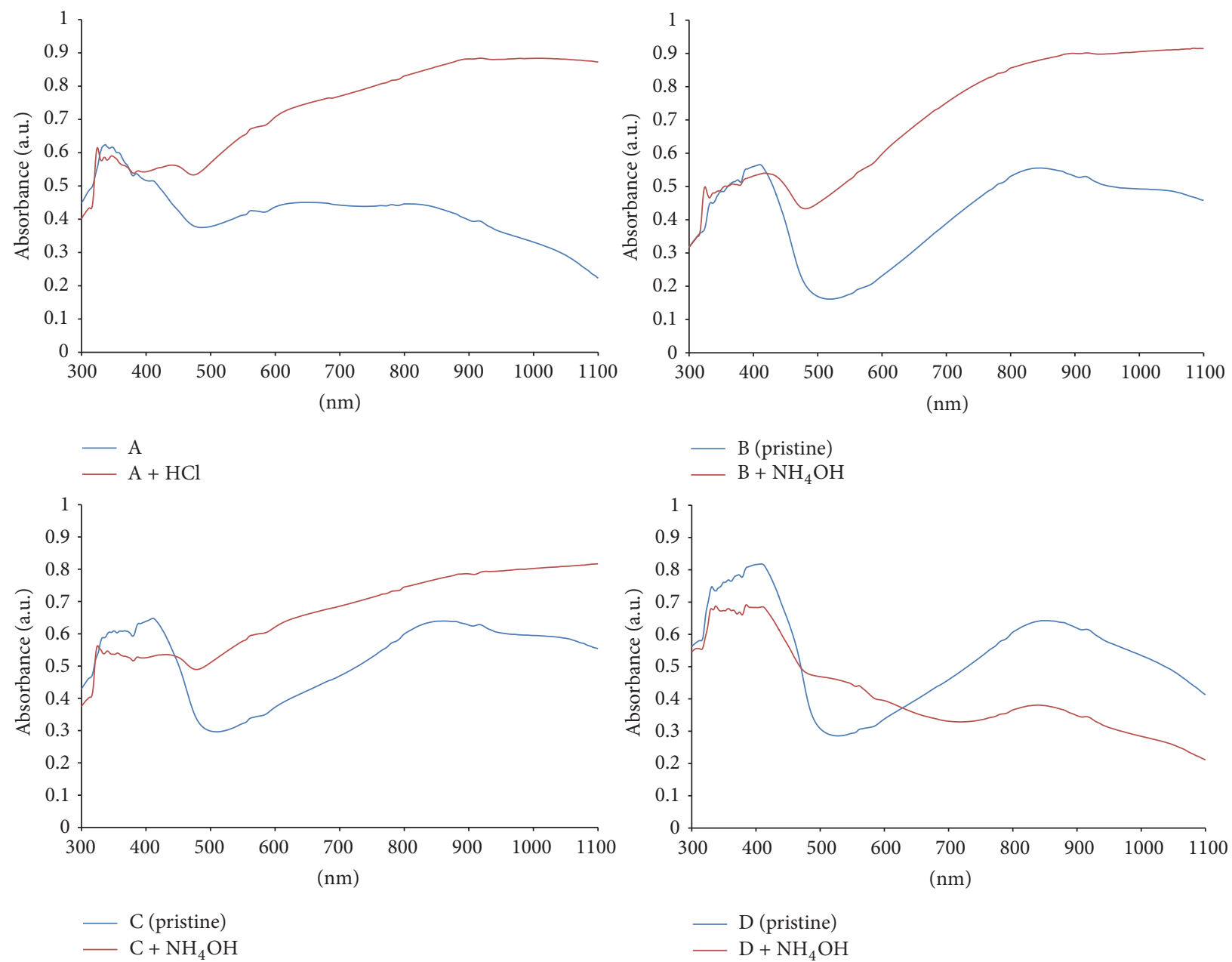

FIGURE 9: Vis-NIR spectra of the membranes before the impact of the analyzed factor (blue) and after treatment with $0.0001 \mathrm{M}(0.1 \mathrm{ppm})$ solution of the test agent (red).

1 ppm of gaseous ammonia, with the detection time of approx. 1 minute.

As already mentioned, acids or bases not only change electrical properties of polyaniline but also change its color. Organoleptic verification of the color is the easiest way to check whether the polymer is in the alkaline or acidic form, but despite its simplicity it is hardly measurable. It seems that the most appropriate measurements determining the color change are the measurements of the electron spectrum of the tested membranes in the visible light range. In the case of polyaniline, where the amount of possible electrons to be excited is high, the adsorption range of the radiation is shifted towards the lower energy waves, that is, towards near infrared. Therefore, in the study, we used a spectrophotometer with measurement range of $190 \mathrm{~nm}$ to $1100 \mathrm{~nm}$.

Nonprotonated form of polyaniline has two characteristic peaks of its electron spectrum image, that is, at $330 \mathrm{~nm}$ and at approx. $630 \mathrm{~nm}$. They are responsible for the passage of electrons in quinone systems of polyaniline. Under the influence of protonating agent (e.g., acid), these bands are shifted towards lower excitation energy, that is, towards near infrared. In case of a good protonating medium, the Vis-NIR spectrum for polyaniline shows two peaks, that is, at approx. $440 \mathrm{~nm}$ and at approx. $850 \mathrm{~nm}$. As a result of improved conformation of polyaniline into being more linear, the second peak $(850 \mathrm{~nm})$ is stretched to the near infrared wavelength range, often reaching its maximum at a wavelength of about $2700 \mathrm{~nm}$. This picture of the spectrum indicates a very good chain conformation and a low excitation energy of valence electrons, which causes their high delocalization along the polymer chain. The macroscopic effect of this phenomenon, apart from the color change, is a very high increase in the conductivity of the polymer. The effect of such favorable change in the electronic structure of polyaniline is obtained by using the appropriate protonating acids. The best additives are acids of the sulfonic acid groups, including the best one, used by the authors: the camphorsulfonic acid (CSA) [52].

Spectroscopic UV-Vis studies were performed for all samples of membranes prepared using methods described in the paper (Figure 9).

For A membranes, polyaniline is in the base form (nonprotonated, blue); therefore its sensitivity to an inorganic 
acid $(\mathrm{HCl})$ was tested. Various concentrations were used and for all tested samples spectrum was obtained on a UVVis spectrophotometer. For all concentrations of acid $(\mathrm{HCl})$, along with the observed visual color change, diametrically different picture of the electron spectrum was observed. It was shown that the use of solutions containing very dilute hydrochloric acid (i.e., at a concentration of $0.001 \mathrm{M}$ ) changes the polyaniline form from alkaline (blue) into acidic (green), as seen in the Vis-NIR spectra. Increasing the concentration of acid does not cause further specific changes in the observed spectrum. The studies have indicated very high sensitivity of the tested A membrane to acid content in the filtered solution. In addition, the increase in the specific surface of the membranes, as demonstrated in other studies, causes a significant increase in their sensitivity to acids.

In the process of forming PAN/PANI membranes, DMF was used as a common solvent for both polymers used. The solvent dissolves only the nonprotonated (blue, nonconductive) form of polyaniline. Three different ways of polyaniline protonation were proposed in order to impart the sensory properties for the detection of basic compounds by the membranes. The first method was based on coagulation of the membrane in water and then washing it with the acid solution, CSA (B membrane); the second was based on coagulation of the membrane in the acid solution, CSA ( $\mathrm{C}$ membrane). In the third method, the application of dried PAN membranes with previously protonated polyaniline solution was used (D membranes). Thus prepared membranes (B, C, and $\mathrm{D})$, comprising polyaniline in the acidic (conductive) form, were subject to the base solutions $\left(\mathrm{NH}_{4} \mathrm{OH}\right)$ at different concentrations.

In all cases, changes in the electron spectrum image were visible already when using the minimum concentration of ammonia (i.e., 0.001 M). However, the obtained spectra are not unambiguous. The best effect of changes in PANI properties from acidic to alkaline was obtained for membranes coated with polyaniline solution ( $\mathrm{D}$ membrane). In this case, the protonation reaction and simultaneous color change take place under the influence of the minimum ammonia concentration. The observed changes indicate high presence of the conductive polymer on the membrane surface, which results in its easy protonation and deprotonation.

Similar results are obtained for B membranes, which were coagulated in water and then rinsed with CSA. In the process of their formation, the polyaniline present on the membrane surface reacted with the acid (CSA), transforming into the conductive form (green). Therefore, as a result of even small amounts of deprotonation agent, good penetration of the membrane surface and polyaniline deprotonation occur. Analyzing the exact electronic spectra of B membranes, low intensity bands shifting to the near infrared were observed. It can, therefore, be concluded that, during washing the membranes with the acid (CSA), it penetrates into the structure of the PANI polymer matrix and the acid stuck in the polymer blocks the base (ammonia).

In the case of $\mathrm{C}$ membranes, PANI deprotonation reaction does not occur completely. In the UV-Vis spectra of membranes treated with ammonia, we can see that the polyaniline still remains largely in the protonated form. This is probably due to the fact that, during membrane formation, at the stage of coagulation with acid (CSA), part of the polyaniline is protonated and is then occluded in the polyacrylonitrile matrix. This is partly supported by studies using FTIR spectroscopy. PANI blocked in this way has no direct contact with deprotonating agent, which is ammonia, and still remains in the doped form. This phenomenon is confirmed by the spectra of membranes for higher concentrations of ammonia. Characteristic bands shifting to the near infrared indicate the presence of the protonated form of polyaniline in the membranes.

\section{Conclusion}

The paper presents the research on the method of obtaining composite polyacrylonitrile membranes doped with polyaniline using phase inversion method. The solvent proposed for preparing the solution was N,N-dimethylformamide, common to both polymers. To protonate PANI, camphorsulfonic acid was used. Membranes were formed by two methods. The first method was to dissolve both polymers (PAN and PANI) and then coagulating in water or in an aqueous solution of camphorsulfonic acid (CSA). The second method consisted in forming the membranes from polyacrylonitrile solution and coagulation in water, followed by coating of CSA-protonated polyaniline with a solution of 2,2,2-trifluoroethanol (TFE). The membranes obtained as a result of the experiment were tested for physical and chemical properties, transport properties (ultrafiltration cell), surface morphology (SEM), degree of dispersion of composite components (FTIR microspectroscopy), and sensitivity to the presence of dilute acids and bases (UV-Vis spectrophotometry).

The use of a homogeneous PAN/PANI solution allows simple and single-step formation of composite membranes by the wet phase inversion method. Polyacrylonitrile doped with polyaniline has an important impact on the process of forming the membrane and thus on the physicochemical and transport properties.

The addition of nonprotonated polyaniline to PAN membranes (A membrane) increases the mass per unit area, thickness, density, porosity, and water sorption. It has, however, no significant effect on the transport properties of the resulting membranes, as confirmed by SEM images. A membrane is sensitive to the presence of a dilute inorganic acid $(\mathrm{HCl})$ already at a concentration of $0.1 \mathrm{ppm}$, despite the fact that the acid is not a good protonating agent.

Protonating of PAN/PANI membranes in the final stage of formation using CSA (B membrane) causes a decrease in the thickness, porosity, and water sorption, with simultaneous increase in density and improvement in the transport properties of these membranes. B membrane, unlike the remaining membranes, can be operated alternately in acidic and basic environment, and its sensitivity is $0.01 \mathrm{ppm}$.

On the other hand, the addition of CSA to the coagulating bath ( $\mathrm{C}$ membrane) results in a significant reduction in thickness, water sorption, and porosity of the membranes. The advantage of $\mathrm{C}$ membrane is low density, which undoubtedly influences the high specific permeate flux values. And 
the sensory properties demonstrated the suitability of this membrane in alkali environment $\left(0.01 \mathrm{ppm} \mathrm{NH}_{4} \mathrm{OH}\right)$. The structure of $\mathrm{C}$ membrane observed by a scanning electron microscope indicates that the cross section of the membrane is characteristic for conventional ultrafiltration membranes.

D membrane, on the other hand, has properties similar to pure PAN membranes (" 0 " membrane). It differs in definitely the worst transport properties of all the membranes. These results may be due to the hydrophobization of the surfaces during distilled water flow, which is observed by the naked eye by color change into dark blue. Composite PAN/PANI membranes manufactured by coating are characterized by the highest content of polyaniline on the surface of both the skin layer and the carrier layer, and UV-Vis spectra show the best protonation and sensitivity to $0.01 \mathrm{ppm}$ of $\mathrm{NH}_{4} \mathrm{OH}$. The big disadvantage of these membranes, however, is the instability of the PANI connection to the polyacrylonitrile matrix.

The conducted studies show that the membranes obtained in the experiment are characterized by a very low contact angle; that is, they are hydrophilic and are not charged electrostatically, which reduces the risk of adverse fouling phenomenon. Furthermore, when choosing the method of membrane forming, we can obtain asymmetric membranes with good physical and chemical and transport properties or ones characterized by high sensitivity to the $\mathrm{pH}$ of the solution.

The obtained membranes can be used as presence sensors of ammonia or dilute acids in landfills, in industrial waste water discharging into rivers, in plants producing explosives, and in public places such as schools, kindergartens, and hospitals. They can also be used as elements of chemical emergency service clothing. In addition, they could be used as presence sensors of ammonia in hygiene materials for children and adults.

\section{Additional Points}

We can highlight the following points:

(i) Composite PAN/PANI membranes were obtained using phase inversion method from a solution in $\mathrm{N}, \mathrm{N}-$ dimethylformamide (DMF), following two methods.

(ii) Different physicochemical properties of membranes were considered by altering the fabrication technique.

(iii) Obtained membranes showed the best sensitivity from $0.01 \mathrm{ppm}$ of $\mathrm{HCl}$ to $0.01 \mathrm{ppm}$ of $\mathrm{NH}_{4} \mathrm{OH}$.

\section{Competing Interests}

The authors declare that they have no competing interests.

\section{References}

[1] G. Wypych, Handbook of Polymers, ChemTec, Ontario, Canada, 2nd edition, 2016.

[2] V. A. Bhanu, P. Rangarajan, K. Wiles et al., "Synthesis and characterization of acrylonitrile methyl acrylate statistical copolymers as melt processable carbon fiber precursors," Polymer, vol. 43, no. 18, pp. 4841-4850, 2002.
[3] P. Gibson, H. Schreuder-Gibson, and D. Rivin, "Transport properties of porous membranes based on electrospun nanofibers," Colloids and Surfaces A: Physicochemical and Engineering Aspects, vol. 187-188, pp. 469-481, 2001.

[4] N. L. Lala, R. Ramaseshan, L. Bojun et al., "Fabrication of nanofibers with antimicrobial functionality used as filters: protection against bacterial contaminants," Biotechnology and Bioengineering, vol. 97, no. 6, pp. 1357-1365, 2007.

[5] L. Feng, S. Li, H. Li et al., "Super-hydrophobic surface of aligned polyacrylonitrile nanofibers," Angewandte ChemieInternational Edition, vol. 41, no. 7, pp. 1221-1223, 2002.

[6] C. Kim, Y. I. Jeong, B. T. N. Ngoc et al., "Synthesis and characterization of porous carbon nanofibers with hollow cores through the thermal treatment of electrospun copolymeric nanofiber webs," Small, vol. 3, no. 1, pp. 91-95, 2007.

[7] M. Peng, D. Li, L. Shen, Y. Chen, Q. Zheng, and H. Wang, "Nanoporous structured submicrometer carbon fibers prepared via solution electrospinning of polymer blends," Langmuir, vol. 22, no. 22, pp. 9368-9374, 2006.

[8] Y. Yang, H. Wang, X. Lu, Y. Zhao, X. Li, and C. Wang, "Electrospinning of carbon/CdS coaxial nanofibers with photoluminescence and conductive properties," Materials Science and Engineering B, vol. 140, no. 1-2, pp. 48-52, 2007.

[9] J. S. Im, S.-J. Park, T. J. Kim, Y. H. Kim, and Y.-S. Lee, “The study of controlling pore size on electrospun carbon nanofibers for hydrogen adsorption," Journal of Colloid and Interface Science, vol. 318, no. 1, pp. 42-49, 2008.

[10] J.-J. Hwang and T.-W. Ma, "Preparation, morphology, and antibacterial properties of polyacrylonitrile/montmorillonite/silver nanocomposites," Materials Chemistry and Physics, vol. 136, no. 2-3, pp. 613-623, 2012.

[11] W. G. Shim, C. Kim, J. W. Lee et al., "Adsorption characteristics of benzene on electrospun-derived porous carbon nanofibers," Journal of Applied Polymer Science, vol. 102, no. 3, pp. 24542462, 2006.

[12] C. Dhand, N. Dwivedi, S. Mishra et al., "Polyaniline-based biosensors," Nanobiosensors in Disease Diagnosis, vol. 2015, no. 4, pp. 25-46, 2015.

[13] T. D. Tran, S. Mori, and M. Suzuki, "Plasma modification of polyacrylonitrile ultrafiltration membrane," Thin Solid Films, vol. 515, no. 9, pp. 4148-4152, 2007.

[14] K. Nouzaki, M. Nagata, J. Arai et al., "Preparation of polyacrylonitrile ultrafiltration membranes for wastewater treatment," Desalination, vol. 144, no. 1-3, pp. 53-59, 2002.

[15] I.-C. Kim, H.-G. Yun, and K.-H. Lee, "Preparation of asymmetric polyacrylonitrile membrane with small pore size by phase inversion and post-treatment process," Journal of Membrane Science, vol. 199, no. 1, pp. 75-84, 2002.

[16] H.-A. Tsai, Y.-L. Ye, K.-R. Lee, S.-H. Huang, M.-C. Suen, and J.-Y. Lai, "Characterization and pervaporation dehydration of heat-treatment PAN hollow fiber membranes," Journal of Membrane Science, vol. 368, no. 1-2, pp. 254-263, 2011.

[17] H. Lohokare, Y. Bhole, S. Taralkar, and U. Kharul, "Poly(acrylonitrile) based ultrafiltration membranes: optimization of preparation parameters," Desalination, vol. 282, pp. 46-53, 2011.

[18] P. Wang, Z. Wang, and Z. Wu, "Insights into the effect of preparation variables on morphology and performance of polyacrylonitrile membranes using Plackett-Burman design experiments," Chemical Engineering Journal, vol. 193-194, pp. 50-58, 2012. 
[19] S. Yang and Z. Liu, "Preparation and characterization of polyacrylonitrile ultrafiltration membranes," Journal of Membrane Science, vol. 222, no. 1-2, pp. 87-98, 2003.

[20] C.-L. Lai, W.-C. Chao, W.-S. Hung et al., "Physicochemical effects of hydrolyzed asymmetric polyacrylonitrile membrane microstructure on dehydrating butanol," Journal of Membrane Science, vol. 490, pp. 275-281, 2015.

[21] J. Wang, C. O. Too, D. Zhou, and G. G. Wallace, "Novel electrode substrates for rechargeable lithium/polypyrrole batteries," Journal of Power Sources, vol. 140, no. 1, pp. 162-167, 2005.

[22] M. Bengoechea, I. Boyano, O. Miguel et al., "Chemical reduction method for industrial application of undoped polypyrrole electrodes in lithium-ion batteries," Journal of Power Sources, vol. 160, no. 1, pp. 585-591, 2006.

[23] B. D. Malhotra, A. Chaubey, and S. P. Singh, "Prospects of conducting polymers in biosensors," Analytica Chimica Acta, vol. 578, no. 1, pp. 59-74, 2006.

[24] M. S. Mansour, M. E. Ossman, and H. A. Farag, "Removal of Cd (II) ion from waste water by adsorption onto polyaniline coated on sawdust," Desalination, vol. 272, no. 1-3, pp. 301-305, 2011.

[25] M. Karimi, M. Mohsen-Nia, and A. Akbari, "Electro-separation of synthetic azo dyes from a simulated wastewater using polypyrrole/polyacrylonitrile conductive membranes," Journal of Water Process Engineering, vol. 4, pp. 6-11, 2014.

[26] A. A. Khan and L. Paquiza, "Characterization and ion-exchange behavior of thermally stable nano-composite polyaniline zirconium titanium phosphate: its analytical application in separation of toxic metals," Desalination, vol. 265, no. 1-3, pp. 242-254, 2011.

[27] R. Li, L. Liu, and F. Yang, "Removal of aqueous $\mathrm{Hg}(\mathrm{II})$ and $\mathrm{Cr}(\mathrm{VI})$ using phytic acid doped polyaniline/cellulose acetate composite membrane," Journal of Hazardous Materials, vol. 280, pp. 20-30, 2014.

[28] B.-H. Lee, H.-J. Kim, and H.-S. Yang, "Polymerization of aniline on bacterial cellulose and characterization of bacterial cellulose/polyaniline nanocomposite films," Current Applied Physics, vol. 12, no. 1, pp. 75-80, 2012.

[29] S. Vulpe, F. Nastase, C. Nastase, and I. Stamatin, "PAN-PAni nanocomposites obtained in thermocentrifugal fields," Thin Solid Films, vol. 495, no. 1-2, pp. 113-117, 2006.

[30] G. Ciric-Marjanovic, "Recent advances in polyaniline research: polymerization mechanisms, structural aspects, properties and applications," Synthetic Metals, vol. 177, pp. 1-47, 2013.

[31] S. Bhadra, D. Khastgir, N. K. Singha, and J. H. Lee, "Progress in preparation, processing and applications of polyaniline," Progress in Polymer Science (Oxford), vol. 34, no. 8, pp. 783-810, 2009.

[32] Z. M. Tahir, E. C. Alocilja, and D. L. Grooms, "Polyaniline synthesis and its biosensor application," Biosensors and Bioelectronics, vol. 20, no. 8, pp. 1690-1695, 2005.

[33] B. Adhikari and S. Majumdar, "Polymers in sensor applications," Progress in Polymer Science, vol. 29, no. 7, pp. 699-766, 2004.

[34] S. Nambiar and J. T. W. Yeow, "Conductive polymer-based sensors for biomedical applications," Biosensors and Bioelectronics, vol. 26, no. 5, pp. 1825-1832, 2011.

[35] Z. Jin, Y. Su, and Y. Duan, "An improved optical pH sensor based on polyaniline," Sensors and Actuators B: Chemical, vol. 71, no. 1-2, pp. 118-122, 2000.

[36] D. Dutta, T. K. Sarma, D. Chowdhury, and A. Chattopadhyay, "A polyaniline-containing filter paper that acts as a sensor, acid, base, and endpoint indicator and also filters acids and bases,"
Journal of Colloid and Interface Science, vol. 283, no. 1, pp. $153-$ 159, 2005.

[37] F. Miao, C. Shao, X. Li et al., "Flexible solid-state supercapacitors based on freestanding electrodes of electrospun polyacrylonitrile@polyaniline core-shell nanofibers," Electrochimica Acta, vol. 176, pp. 293-300, 2015.

[38] W. Pan, S. L. Yang, G. Li, and J. M. Jiang, "Electrical and structural analysis of conductive polyaniline/polyacrylonitrile composites," European Polymer Journal, vol. 41, no. 9, pp. 21272133, 2005.

[39] S. J. Lee, H. J. Oh, H. A. Lee, and K. S. Ryu, "Fabrication and physical properties of conductive polyacrylonitrile-polyaniline derivative fibers," Synthetic Metals, vol. 135-136, pp. 399-400, 2003.

[40] G. Zhai, Q. Fan, Y. Tang, Y. Zhang, D. Pan, and Z. Qin, "Conductive composite films composed of polyaniline thin layers on microporous polyacrylonitrile surfaces," Thin Solid Films, vol. 519, no. 1, pp. 169-173, 2010.

[41] A. A. Khan and M. Khalid, "Preparation, FTIR spectroscopic characterization and isothermal stability of differently doped conductive fibers based on polyaniline and polyacrylonitrile," Synthetic Metals, vol. 160, no. 7-8, pp. 708-712, 2010.

[42] H. Xue and Z. Shen, "A highly stable biosensor for phenols prepared by immobilizing polyphenol oxidase into polyanilinepolyacrylonitrile composite matrix," Talanta, vol. 57, no. 2, pp. 289-295, 2002.

[43] Y. H. Park and C. R. Park, "Preparation of conducting polyacrylonitrile/polyaniline composite films by electrochemical synthesis and their electroactivity," Synthetic Metals, vol. 118, no. 1-3, pp. 187-192, 2001.

[44] G. Bayramoglu, A. Ü. Metin, and M. Y. Arica, "Surface modification of polyacrylonitrile film by anchoring conductive polyaniline and determination of uricase adsorption capacity and activity," Applied Surface Science, vol. 256, no. 22, pp. 67106716, 2010.

[45] R. Fryczkowski, M. Gorczowska, B. Fryczkowska, and J. Janicki, "The effect of solvent on the properties of nanofibres obtained by electrospinning from a mixture of poly(3-hydroxybutyrate) and polyaniline," Synthetic Metals, vol. 166, no. 1, pp. 14-21, 2013.

[46] B. Fryczkowska, M. Sieradzka, E. Sarna, R. Fryczkowski, and J. Janicki, "Influence of a graphene oxide additive and the conditions of membrane formation on the morphology and separative properties of poly(vinylidene fluoride) membranes," Journal of Applied Polymer Science, vol. 132, no. 46, Article ID 42789, 2015.

[47] S. Zinadini, A. A. Zinatizadeh, M. Rahimi, V. Vatanpour, and H. Zangeneh, "Preparation of a novel antifouling mixed matrix PES membrane by embedding graphene oxide nanoplates," Journal of Membrane Science, vol. 453, pp. 292-301, 2014.

[48] Y. Feng, G. Han, L. Zhang et al., "Rheology and phase inversion behavior of polyphenylenesulfone (PPSU) and sulfonated PPSU for membrane formation," Polymer, vol. 99, pp. 72-82, 2016.

[49] D. Pal, S. Neogi, and S. De, "Surface modification of polyacrylonitrile co-polymer membranes using pulsed direct current nitrogen plasma," Thin Solid Films, vol. 597, pp. 171-182, 2015.

[50] Z. Fan, Z. Wang, M. Duan, J. Wang, and S. Wang, "Preparation and characterization of polyaniline/polysulfone nanocomposite ultrafiltration membrane," Journal of Membrane Science, vol. 310, no. 1-2, pp. 402-408, 2008.

[51] J. Ren and J. R. McCutcheon, "Polyacrylonitrile supported thin film composite hollow fiber membranes for forward osmosis," Desalination, vol. 372, pp. 67-74, 2015. 
[52] A. G. MacDiarmid and A. J. Epstein, "Secondary doping in polyaniline," Synthetic Metals, vol. 69, no. 1-3, pp. 85-92, 1995.

[53] A. T. Hoang, Y. B. Cho, J.-S. Park, Y. Yang, and Y. S. Kim, "Sensitive naked-eye detection of gaseous ammonia based on dye-impregnated nanoporous polyacrylonitrile mats," Sensors and Actuators, B: Chemical, vol. 230, pp. 250-259, 2016. 

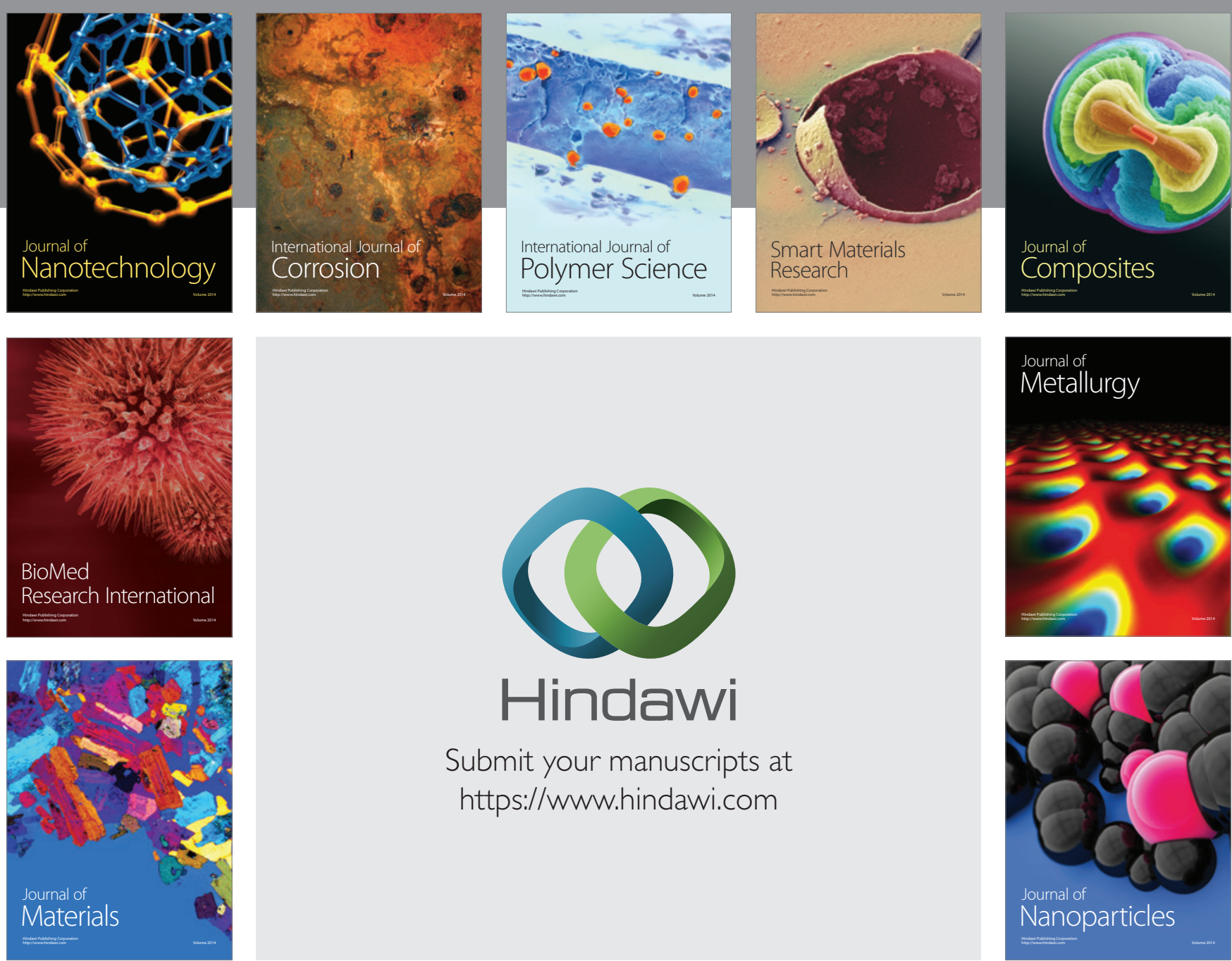

\section{Hindawi}

Submit your manuscripts at

https://www.hindawi.com

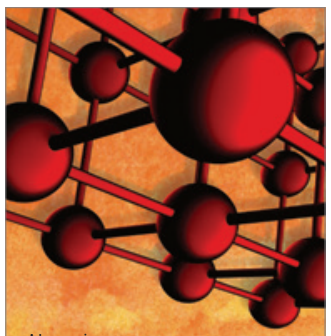

Materials Science and Engineering
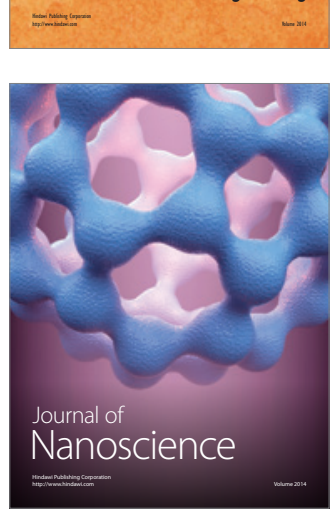
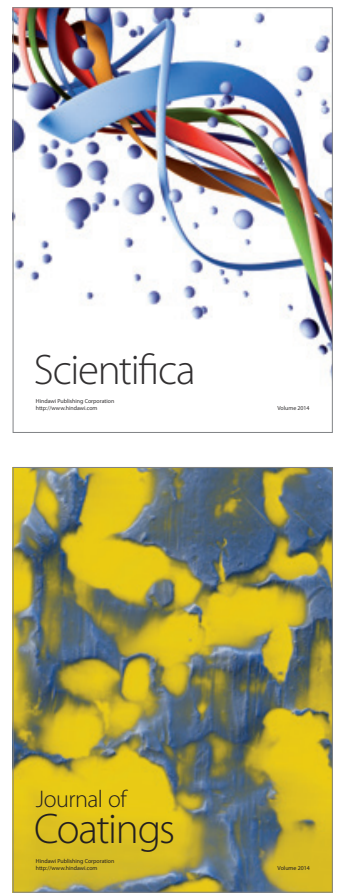
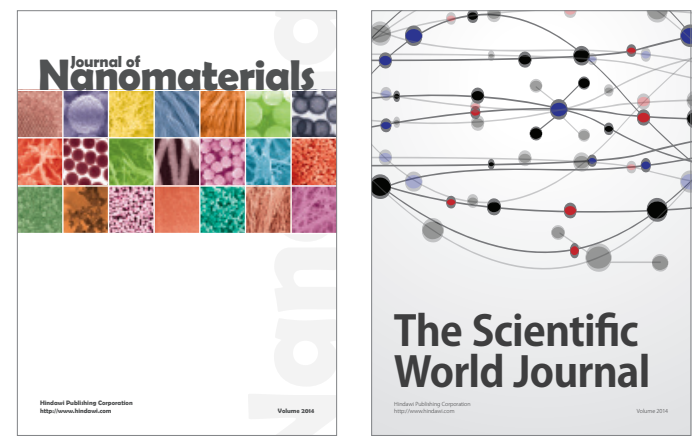

The Scientific World Journal
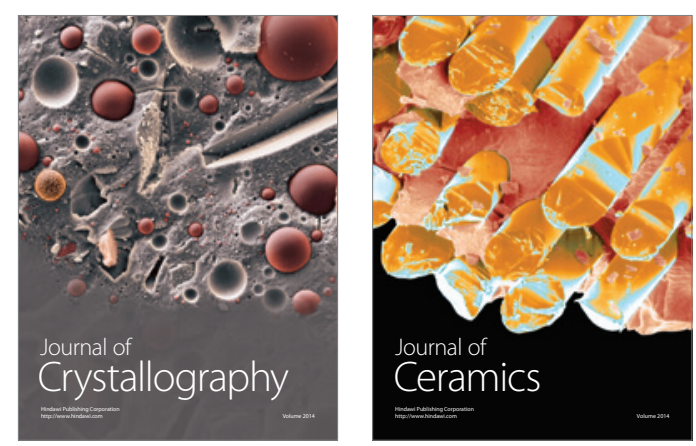
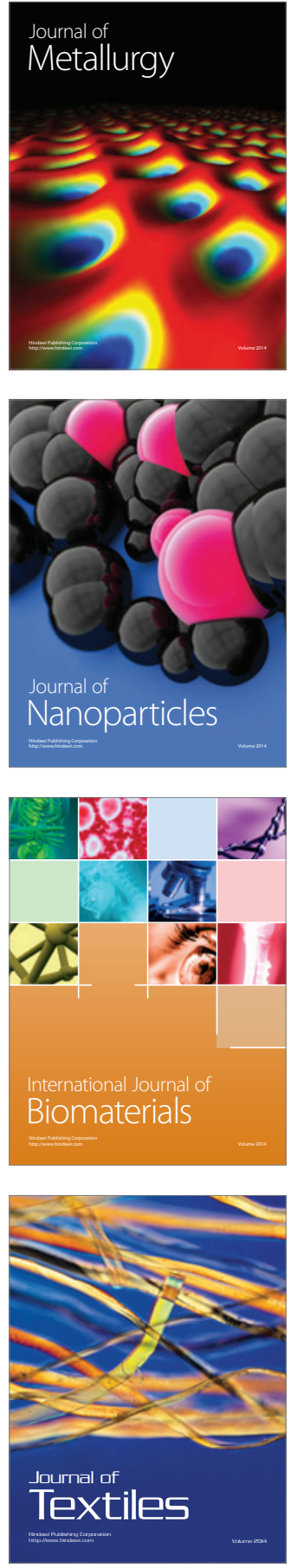